\title{
Dipoles of the South East Madagascar Current
}

\author{
W. Ridderinkhof, ${ }^{1}$ D. Le Bars, ${ }^{1}$ A. S. von der Heydt, ${ }^{1}$ and W. P. M. de Ruijter ${ }^{1}$ \\ Received 14 November 2012; revised 10 January 2013; accepted 10 January 2013; published 13 February 2013.
}

[1] Satellite altimetry data covering 18 years together with hydrographic observations around south Madagascar show that after separation from the coast, the South East Madagascar Current (SEMC) propagates southwestward and breaks up into a regular series of symmetric counterrotating vortex pairs. Most of them split and propagate into the Agulhas retroflection system. Interannual variability of the dipole formation is related to the El Nino-Southern Oscillation. In the observation period two "early" Agulhas retroflection events appeared both related to strong Madagascar dipoles. The symmetry of the dipoles may originate from the boundary current where negative vorticity on the inshore side is adjacent to positive vorticity further offshore. Citation: Ridderinkhof, W., D. Le Bars, A. S. von der Heydt and W. P. M. de Ruijter (2013), Dipoles of the South East Madagascar Current, Geophys. Res. Lett., 40, 558-562, doi:10.1002/ grl.50157.

\section{Introduction}

[2] The southern branch of the East Madagascar Current (SEMC) transports $\sim 35 \mathrm{~Sv}\left(1 \mathrm{~Sv}=1 \times 10^{6} \mathrm{~m}^{3} \mathrm{~s}^{-1}\right)$ of warm Indian Ocean waters poleward [Swallow et al., 1988; Nauw et al., 2008]. This deep-reaching current is one of the sources of the Agulhas Current (AC), the major western boundary current of the South Indian Ocean.

[3] Interest in the SEMC stems from its possible role in the shedding of rings at the Agulhas Retroflection and the associated leakage of Indian Ocean waters into the Atlantic that may have an important impact on the strength and stability of the Atlantic overturning circulation [Beal et al., 2011]. Eddies originating in the Mozambique Channel and in the region south of Madagascar may affect the timing of ring formation at the retroflection of the AC [Schouten et al., 2002; Penven et al., 2006].

[4] The flow system around the southern tip of Madagascar is complex. From an analysis of satellite altimeter data combined with model output, it was suggested that after separating from the coast, the SEMC bifurcates [Siedler et al., 2009] with one branch retroflecting and connecting to the South Indian Ocean Countercurrent (SICC) [Siedler et al., 2006; Palastanga et al., 2007] and the other branch feeding into the Agulhas, partly in the form of eddies and dipoles [de Ruijter et al., 2004].

All Supporting Information may be found in the online version of this article.

${ }^{1}$ Institute for Marine and Atmospheric Research, Utrecht University, Utrecht, The Netherlands.

Corresponding author: W. Ridderinkhof, Institute for Marine and Atmospheric Research, Utrecht University, PO Box 80.005, Utrecht 3508 TA, The Netherlands. (W.Ridderinkhof@uu.nl)

(C)2013. American Geophysical Union. All Rights Reserved. 0094-8276/13/10.1002/grl.50157
[5] However, in situ hydrographic observations do not support such an interpretation. They have revealed that the SICC is a shallow current (limited to $\sim 200 \mathrm{~m}$ depth) [Palastanga et al., 2007], with water mass characteristics that differ from those of the SEMC; instead the SICC characteristics appeared to match with those of the Agulhas Current recirculation [Figure 6d of Nauw et al., 2008].

[6] There is an abundance of eddies in the region around south Madagascar. Cyclonic cells have been observed on the inshore side of the SEMC south of Madagascar [DiMarco et al., 2000; Lutjeharms and Machu, 2000; Machu et al., 2002]. Cyclones and anticyclones propagate south and westward from Madagascar, many into the AC region [Quartly and Srokosz, 2004; Quartly et al., 2006; de Ruijter et al., 2005]. The variability extends eastward in a band around $25^{\circ} \mathrm{S}$ and is related to baroclinic instability of the SICC [Palastanga et al., 2007].

[7] During the 2001 ACSEX hydrographic cruise (Agulhas Current Sources Experiment [de Ruijter et al., 2006], a large counter-rotating vortex pair was encountered southwest of Madagascar [de Ruijter et al., 2004]. It was a mature dipolar structure, deep-reaching $(>2000 \mathrm{~m})$ and with a horizontal extent of $\sim 600 \mathrm{~km}$. The water mass characteristics of the anticyclonic lobe were identical to those of the SEMC. The cyclonic lobe had drawn its waters with Mozambique Channel (MC) characteristics from the inshore side of the SEMC after separation. That seemed to provide supporting evidence for the suggestion that the anticyclone was the result of a retroflection and loop occlusion of the separated SEMC jet, whereas the cyclone was formed as a lee eddy at the inshore side of the separating SEMC.

[8] LaCasce and Isachsen [2007] proposed that the formation of cyclones and anticyclones is caused by barotropic instability of a steady state westward zonal jet, being the continuation of the SEMC. The basic steady state of their model is linear frictional, also in the separation region south of the island. However, straightforward scaling shows that inertial processes are dominant in this region. A steady basic state of the nonlinear system may even not exist [Nof and Pichevin, 1996; van Leeuwen and de Ruijter, 2009]. Nevertheless, an important general characteristic of the model of LaCasce and Isachsen [2007] is that the far-field conditions for the boundary layer around the tip of the island preclude an eastward connection of the SEMC. Allowing for nonlinearities does not change that basic characteristic.

[9] Combined TOPEX-POSEIDON/ERS altimetry data around south Madagascar over the period 1995-2000 showed regular appearance of dipoles in the SEMC separation region [de Ruijter et al., 2004]. A regular sequence of Madagascar dipoles in 2000 interacted a year later with the AC, which resulted in an "early retroflection," an extremely eastward position of the retroflection loop of the AC. Periods of enhanced dipole formation seemed to coincide with negative phases of the El Nino-Southern Oscillation (ENSO) 
[Tourre and White, 1997] and the Indian Ocean Dipole (IOD) [Saji et al., 1999]. However, Palastanga et al. [2006] showed a significant correlation of the IOD index with the strength of the North East Madagascar Current and the eddy production in the Mozambique Channel, but they could not find such an influence of the IOD on the eddy formation south of Madagascar.

[10] With the availability of (almost) 20 years of satellite altimetry (October 1992 to January 2011), it is timely to address the above issues again using the longer time series. This will shed light on whether or not the SEMC retroflects as well as the role of eddies played in the observed variability of that region.

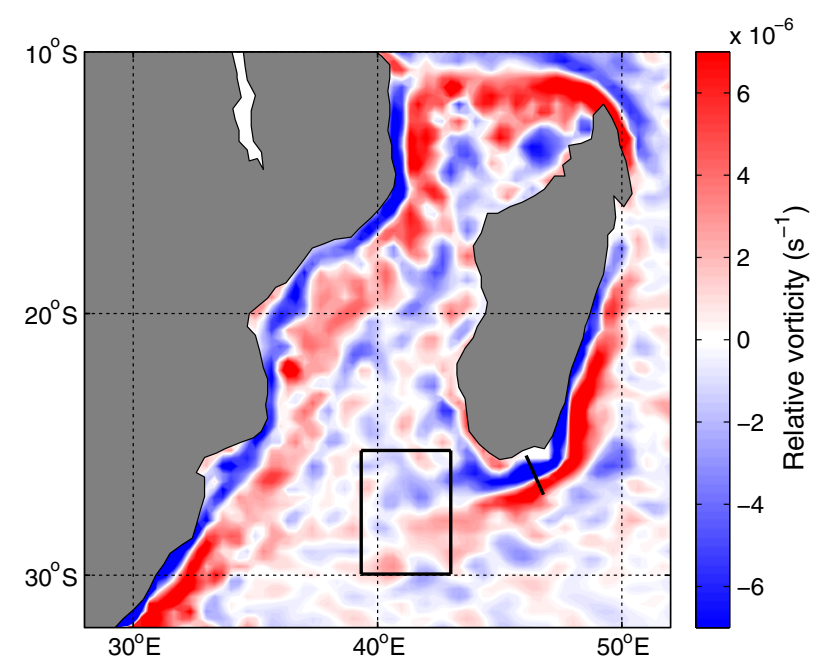

Figure 1. Mean relative vorticity around Madagascar. The black rectangle indicates where the average EKE is determined as a measure for the variability southwest of Madagascar. The black line indicates the satellite transect over which the surface velocity of the SEMC is determined.

\section{Data and Methods}

[11] For the analysis, satellite altimeter data produced by Ssalto/Duacs and distributed by AVISO, with support from Cnes (http://www.aviso.oceanobs.com/duacs/) are used. Data sets with a temporal resolution of 1 week of sea surface anomaly (SSA), dynamic topography, and geostrophic velocities provided on a $\frac{1}{3}^{\circ} \times \frac{1}{3}^{\circ}$ grid are used to observe the mesoscale activity around Madagascar and the AC. Surface velocities of the SEMC are obtained from higher spatial resolution alongtrack satellite data along a transect that crosses the SEMC south of Madagascar (shown in Figure 1); these data have a temporal resolution of 9.9 days.

[12] As a measure for the variability of the eddy formation south of Madagascar from the gridded data of geostrophic velocities a time series of the mean Eddy Kinetic Energy $(\mathrm{EKE}), \mathrm{EKE}=\left(u^{\prime 2}+v^{\prime 2}\right) / 2$, is calculated in a box southwest of Madagascar (shown in Figure 1). Here $u^{\prime}$ and $v^{\prime}$ are the zonal and meridional velocity anomalies, with respect to their temporal mean, respectively. The box $\left(39.3^{\circ} \mathrm{E}-43.0^{\circ} \mathrm{E}\right.$, $25.2^{\circ} \mathrm{S}-30^{\circ} \mathrm{S}$ ) is located at some distance from the SEMC separation but its average continuation runs through it. The passage of an eddy or dipolar structure through the box will result in enhanced values of the EKE time series.

[13] To investigate the influence of ENSO on the variability southwest of Madagascar, the time series of the NINO3.4 index provided by the Ocean Observation Panel for Climate (http://ioc-goos-oopc.org/index.php) is used.

\section{Regular Formation of Symmetric Dipoles South of Madagascar}

[14] Typical formation of dipoles south of Madagascar is shown in the top row of Figure 2. Regular occurrence of peaks in the time series of the mean EKE in a box southwest of Madagascar reflects the passage of eddies at a frequency of about 4-6 per year (Figure 3 top and middle panels).
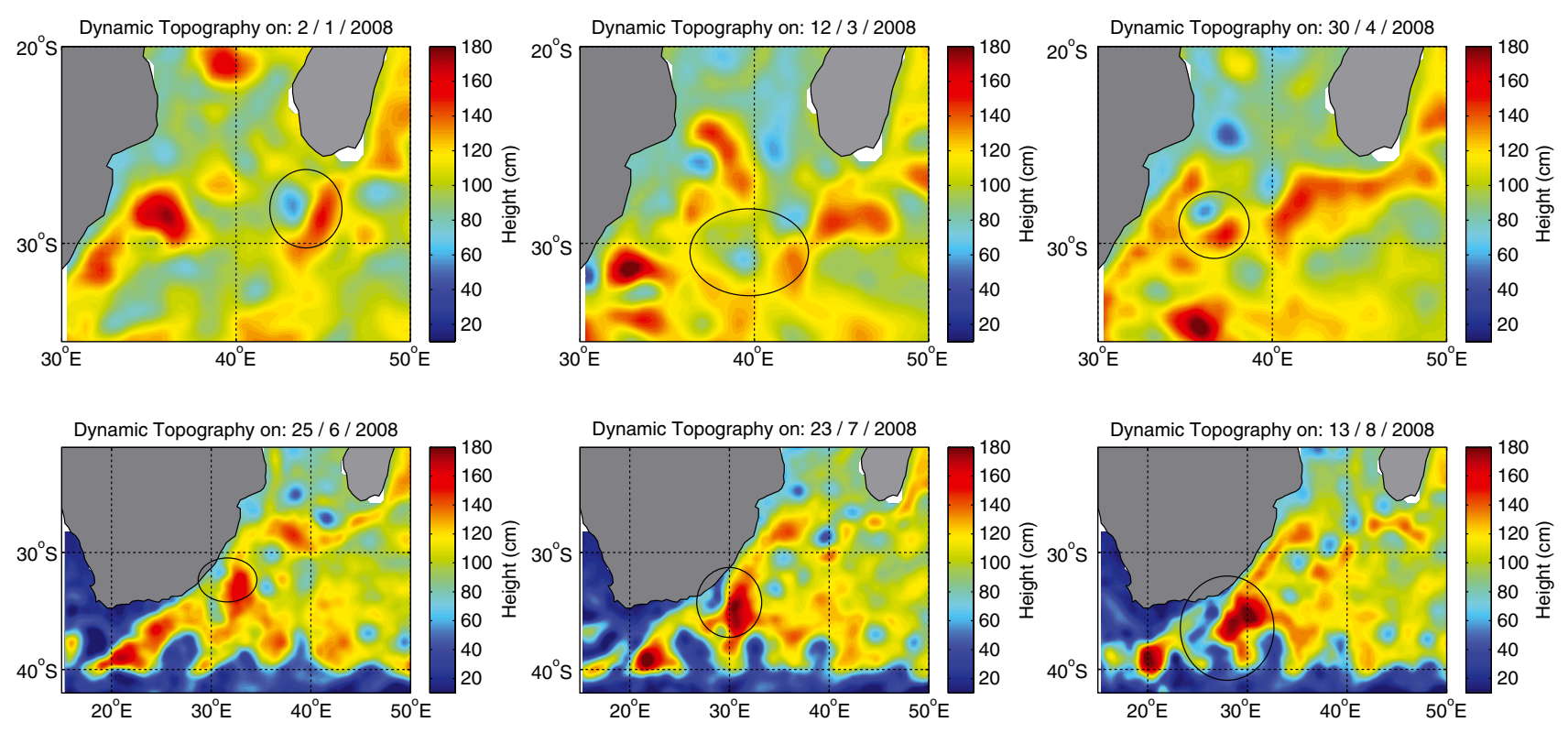

Figure 2. Dynamic topography at different dates shows the path of a dipolar structure created south of Madagascar (top of left column) that leads to an early retroflection event. The cyclone of the structure triggers a cyclonic meander in the Agulhas Current (bottom of left column) which eventually causes the early retroflection in August 2008 (bottom of right column). 

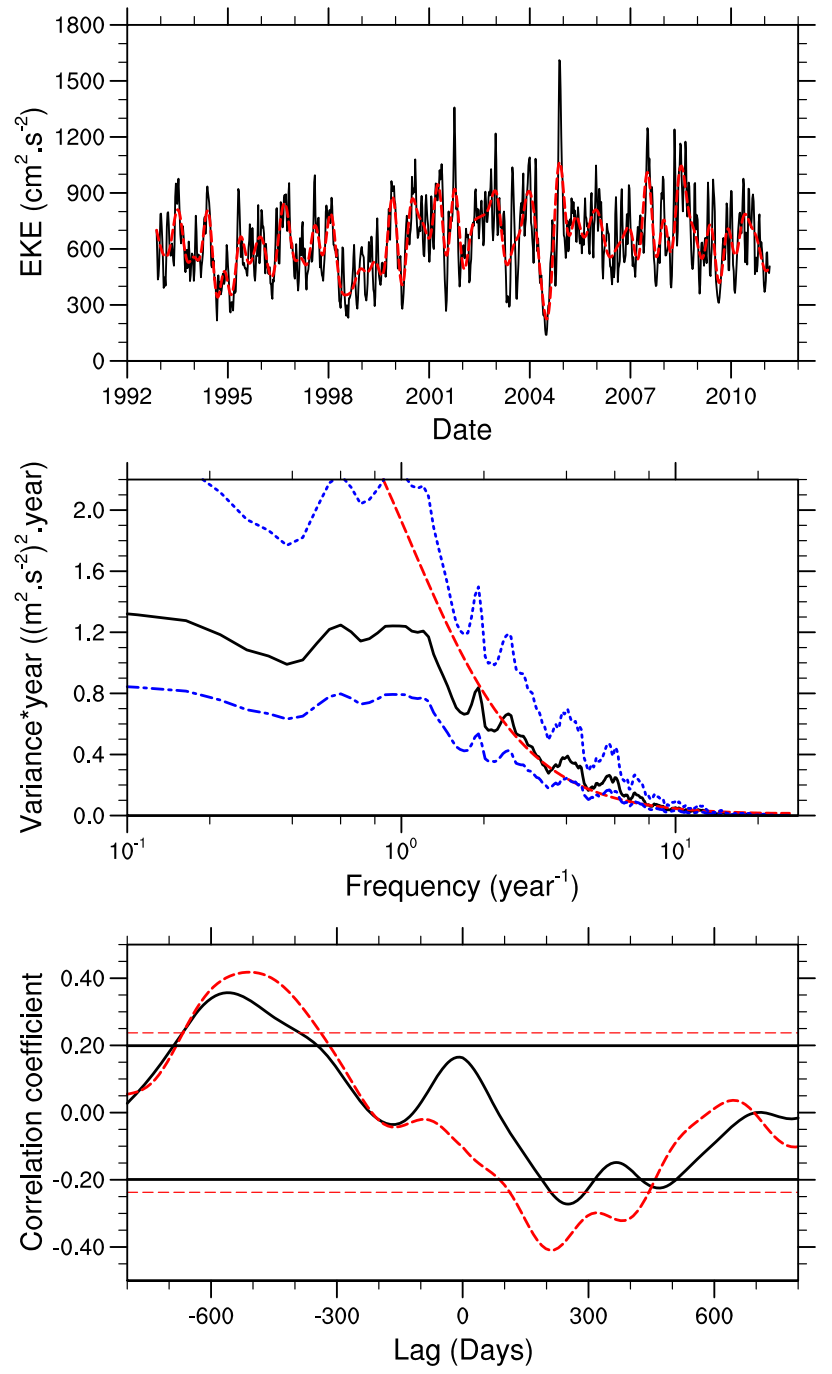

Figure 3. Time series of the mean EKE in the rectangle (see Figure 2.) southwest of Madagascar (low-pass filtered shown in red; top panel). Variance-conserving spectrum of the EKE time series. The red line shows the 95\% red noise confidence interval and the blue dotted lines the 95\% confidence interval of the spectra estimates (middle panel). Crosscorrelation between the low-pass filtered time series of the NINO3.4 index and the strength of the SEMC (red dashed line) and between the NINO3.4 index and the EKE southwest of Madagascar (black line) (bottom panel). For both, the $95 \%$ significance interval is shown by horizontal lines in corresponding color.

Consecutive patterns of the dynamic topography show that these eddies are regularly being formed as dipoles from the SEMC after separation of the jet from the island. The mean direction of the central jet is west to southwestward (Figure 2) with considerable directional variations. The vortex pairs behave irregularly; they interact with other eddies that they encounter and often break up into separated independent eddies.

[15] The dipoles appear quite symmetric. This is reflected in the averaged field of relative vorticity (Figure 1) which is revealed southwest of the island in a characteristic pattern of contra-rotating lobes of about equal strength.

[16] The continuous production of dipoles south of Madagascar is also clearly visible in Hovmuller diagrams of the time evolution of the dynamic topography over a transect southwest of Madagascar (between $42.5^{\circ} \mathrm{E}, 25.0^{\circ} \mathrm{S}$ and $45.0^{\circ} \mathrm{E}, 29^{\circ} \mathrm{S}$ ). The period shown in Figure 4 (November 1999 to November 2001) includes the dipole that was observed at sea [de Ruijter et al., 2004]. The frequency of dipoles crossing this transect is $4-6 \mathrm{yr}^{-1}$. A smaller number reach the EKE box (Figure 1) because part of them merge with other eddies soon after separation. (Hovmuller diagrams of the entire period between 1993 and 2010 have been added as Supporting Information to this paper, and also a movie that shows the continuous production of the dipoles has been added).

[17] Variation in strength of the SEMC is related to the formation of the dipoles. A correlation coefficient of 0.36 (significantly different from 0 to the $95 \%$ confidence interval) at a lag of 40 days was found between the EKE and the SEMC strength at the altimetry ground track across the SEMC.

\section{Symmetry of Dipoles}

[18] The conditions for the symmetry of the vortex pairs are probably set in the SEMC. At the separation from the southern tip of Madagascar, there is an approximately equal amount of cyclonic and anticyclonic shear across the jet of the SEMC (in agreement with "Stewarts constraint" [Stewart, 1989]). These properties are then approximately conserved after the jet has separated from the island. It could explain the symmetric development of the counter-rotating dipole vortices.

[19] Surprisingly, these observations indicate the development of both lobes of the dipoles without a retroflection of the SEMC. The expansion of the dipoles seems to be firstorder driven by the high cyclonic and anticyclonic shear across the jet at separation, where the asymmetry induced by the beta effect is negligible. An estimate of the importance of beta is given by the beta-Rossby number, $U /\left(\beta L^{2}\right)$, which is $\mathrm{O}(10)$ for the high shears observed at separation, where characteristic values for the SEMC are $U=1 \mathrm{~ms}^{-1}$ and $L=100 \mathrm{~km}$.

\section{Interannual Variability}

[20] Interannual variability of the strength of the SEMC and thereby of the EKE southwest of Madagascar appears to be related to ENSO. Figure 3 (bottom panel) shows the cross-correlation between the strength of the SEMC and the NINO3.4 index as well as that between the EKE southwest of Madagascar and the NINO3.4 index (prior to calculating the cross-correlations, all time series were low-pass filtered with a 3 cpy Kaiser window). Both the strength of the SEMC and the EKE have a significant positive correlation with the NINO3.4 index leading the index by approximately 500 days and a significant negative correlation lagging the index by approximately 250 days. This implies that after an El Nino (La Nina) event, there is a period in which the SEMC is weaker (stronger), and there is less (more) EKE observed southwest of Madagascar, while prior to an El Nino (La Nina) event, the opposite occurs. Evaluation of the cross correlation between the SSA field of the Indian Ocean and the NINO3.4 index (not shown) indicates that ENSO influences the region around Madagascar in a similar manner as the IOD [Palastanga et al., 2006], by generating large westward-propagating anomalies in the southern tropical Indian Ocean. 

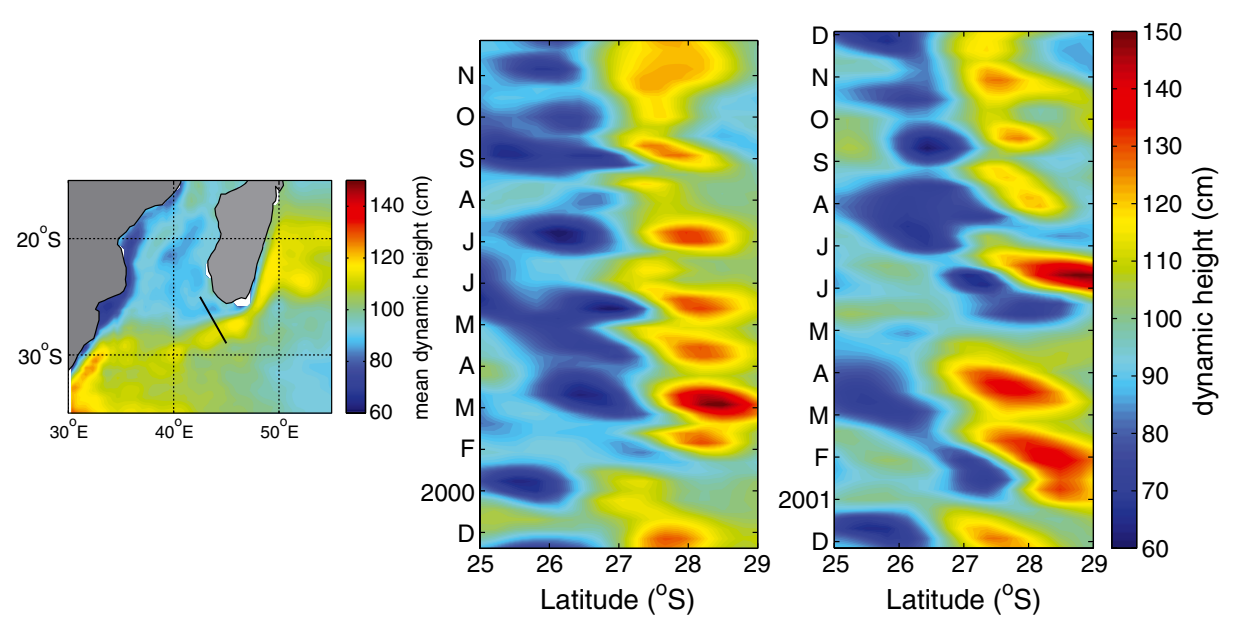

Figure 4. Hovmuller transect shown on top of the mean dynamic topography in the region around the southwest of Madagascar (left panel). Hovmuller diagrams that cover the period November 1999 to November 2001, showing the regular occurrence of dipolar structures (middle and right panels).

\section{Decadal Variability: Early Retroflection of the Agulhas}

[21] To investigate the frequency of early retroflection events of the AC and the role of the Madagascar Dipoles, the gridded data of geostrophic velocities are used to analyze the surface transport of the part of the AC that flows south of Africa. Meridionally integrated zonal velocities are calculated over transects that are placed over the $\mathrm{AC}$ to obtain the zonal surface transport of the AC at different longitudes (Figure 5). Before integrating over the transect, all eastward velocities were set to zero. This prevents a northward meander of the Agulhas Return Current (ARC) to have an impact on the presumed zonal Agulhas transport.

[22] A thus derived time series of the westward surface transport anomaly at the different meridional longitudes shows only two early retroflection events: the one starting in December 2000 [de Ruijter et al., 2004] and one in 2008 [Rouault et al., 2010] (large negative anomalies in Figure 5). Our analysis links both events to Madagascar dipoles (Figure 2 shows the 2008 event). During both events, interaction of the dipoles with the highly sheared $\mathrm{AC}$ induced the growth of both the cyclonic and anticyclonic lobes (Figure 2), likely fed by the release of barotropic instability [de Ruijter et al., 1999; Tsugawa and Hasumi, 2010]. These growing perturbations propagated downstream where they interacted with the meandering ARC. Timing was such that together they established a short circuiting of the AC retroflection loop. Transport anomalies of the opposite sign occur also (Figure 5, positive anomalies in 1997, 1999, and 2010) and are caused by cyclonic and anticyclonic lobes similar to the early retroflection events. However, due to a different interaction with the ARC, these lobes continued along the $\mathrm{AC}$, transporting an anomalous volume of water towards the $\mathrm{AC}$ retroflection.

\section{Summary and Discussion}

[23] From an analysis using almost 20 years of satellite altimetry data and in situ observations, we have shown that
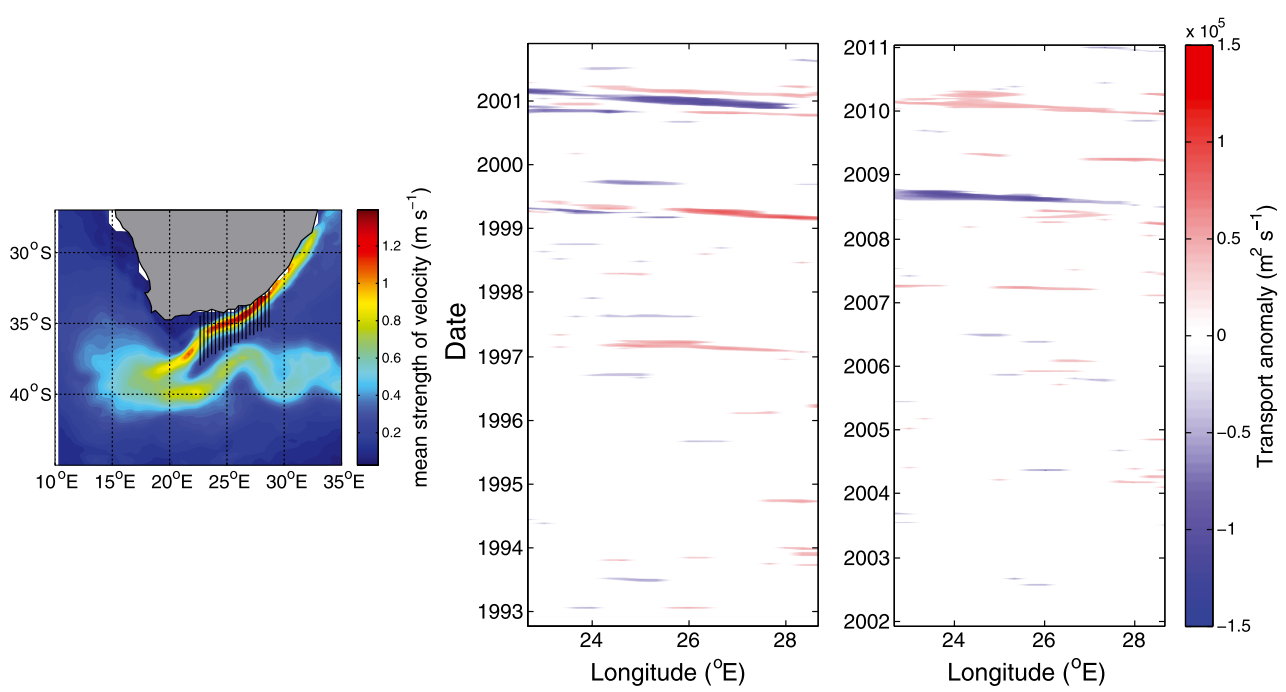

Figure 5. Meridional transects over which the westward surface transport is calculated (black lines) together with the mean strength of the velocity at each location (color scale) (top panel). Time series of the anomalous westward surface transport at the different meridional transects, with only anomalies larger than two standard deviations are shown (bottom panel). 
at the southern tip of Madagascar the SEMC breaks up in a series of nearly symmetric dipolar vortex pairs of approximately zero net relative vorticity. They appear at a frequency of about 4-6 per year. Most vortex pairs break up shortly after their formation and interact with previously formed cyclones and anticyclones.

[24] The velocity shear across the SEMC is so large that the dynamics of the evolution of the dipole is dominantly nonlinear. A surprising consequence is that there is no retroflection of the SEMC nor does it continue as an unstable westward jet. Instead the lobes develop symmetrically and the dynamics appear more similar to that of modon formation [Flierl et al., 1983].

[25] The EKE south of Madagascar was shown to correlate with the strength of the SEMC prior to separation. Such a relationship could not be found by Palastanga et al. [2006] probably because they used a more upstream satellite transect to determine the surface velocity of the SEMC. Within the SEMC, there is a short decorrelation length scale (also observed in the Gulf Stream [Sturges and Hong, 2001]), and the velocity at our transect does not significantly correlate with the velocity at locations further than $450 \mathrm{~km}$ upstream.

[26] The very early retroflection of the AC in 2001 was an exceptional one. Only one more appeared in the 18 year period (in 2008). In both cases, it needed a concerted action of cyclonic meanders of the AC and the ARC to shortcut the retroflection loop with an active role of the Madagascar dipoles in generating the Agulhas cyclones.

[27] Interannual variability in the separation region appeared related with the ENSO cycle, but not significantly with the IOD. Significant correlations were found between the NINO3.4 index and both the strength of the SEMC and the EKE southwest of Madagascar. Positive and negative lags are between 250 and 500 days. Preceding a positive (negative) ENSO phase, stronger (weaker) velocities in the SEMC were observed. Following a positive (negative) phase, weaker (stronger) velocities in the SEMC were observed. We are presently investigating the possible explanations of these relations and their impact.

[28] Acknowledgments. This research was partly funded by the Netherlands organization for Scientific Research (NWO) via the INATEX program (contract ZKO 839.08.430). We thank Steven DiMarco and an anonymous reviewer for their useful suggestions.

\section{References}

Beal, L., W. de Ruijter, A. Biastoch, R. Zahn, and S. W. G. 136 (2011), On the role of the Agulhas system in ocean circulation and climate, Nature, 472, 429-436, doi:10.1038/nature09983.

de Ruijter, W., P. van Leeuwen, and J. Lutjeharms (1999), Generation and evolution of natal pulses, solitary meanders in the Agulhas current, J. Phys. Oceanogr., 29, 3043-3055, doi:10.1175/1520-0485(1999) $029<3043 \mathrm{GAENP}>2.0 . \mathrm{CO} ; 2$.

de Ruijter, W., H. van Aken, E. Beier, J. Lutjeharms, R. Matano, and M. Schouten (2004), Eddies and dipoles around south Madagascar: Formation, pathways and large-scale impact, Deep Sea Res., 51, 383-400, doi:10.1016/j.dsr.2003.10.011.

de Ruijter, W., H. Ridderinkhof, and M. Schouten (2005), Variability of the southwest Indian Ocean, Philos. Trans. R. Soc., 363, 63-76, doi:10.1098/ rsta.2004.1478. de Ruijter, W., G. Brummer, S. Drijfhout, J. Lutjeharms, F. Peters, H. Ridderinkhof, H. van Aken, and P. van Leeuwen (2006), Observations of the inter-ocean exchange around South Africa, EOS, Trans. Am. Geophys. Un., 87(9), 97-101, doi:10.1029/2006EO090002.

DiMarco, S. F., P. Chapman, and W. D. Nowlin Jr. (2000), Satellite observations of upwelling on the continental shelf south of Madagascar, Geophys. Res. Lett., 27(24), 3965-3968, doi:10.1029/2000GL012012.

Flierl, G., M. Stern, and J. Whitehead Jr. (1983), The physical significance of modons: Laboratory experiments and general integral constraints, Dyn. Atmos. Oceans, 7(4), 233-263, doi:10.1016/j.bbr.2011.03.031.

LaCasce, J., and P. Isachsen (2007), On Sverdrup discontinuities and vortices in the southwest Indian Ocean, J. Phys. Oceanogr., 37, 2940-2950, doi:10.1175/2007JPO3652.1.

Lutjeharms, J.R.E., and E. Machu (2000), An upwelling cell inshore of the East Madagascar Current, Deep Sea Res. Part I: Oceanogr. Res. Pap., 47(12), 2405-2411, doi:10.1016/S0967-0637(00)00026-1.

Machu, E., J. R. E. Lutjeharms, A. M. Webb, and H. M. Van Aken (2002), First hydrographic evidence of the southeast Madagascar upwelling cell, Geophys. Res. Lett., 29(21), doi:10.1029/2002GL015381.

Nauw, J., H. van Aken, A. Webb, J. Lutjeharms, and W. de Ruijter (2008), Observations of the southern east Madagascar current and undercurrent and countercurrent system, J. Geophys. Res., 113, C08,006, doi:10.1029/2007JC004639.

Nof, D., and T. Pichevin (1996), The retroflection paradox, J. Phys. Oceanogr., 26(11), 2344-2358.

Palastanga, V., P. van Leeuwen, and W. de Ruijter (2006), A link between low-frequency mesoscale eddy variability around Madagascar and the large-scale Indian Ocean variability, J. Geophys. Res., 111, C09,029, doi:10.1029/2005JC003081.

Palastanga, V., P. van Leeuwen, M. Schouten, and W. de Ruijter (2007), Flow structure and variability in the subtropical Indian Ocean: Instability of the South Indian Ocean Countercurrent, J. Geophys. Res., 112, C01,001, doi:10.1029/2005JC003395.

Penven, P., J. Lutjeharms, and P. Florenchie (2006), Madagascar: A pacemaker for the Agulhas current system?, Geophys. Res. Lett., 33, doi:10.1029/2006GL026854.

Quartly, Q., and M. Srokosz (2004), Eddies in the southern Mozambique Channel, Deep Sea Res. II, 51, 69-83, doi:10.1016/j. dsr2.2003.03.001.

Quartly, Q., J. Buck, M. Srokosz, and A. Coward (2006), Eddies around Madagascar-The retroflection re-considered, J. Mar. Syst., 63, 115-129, doi:10.1016/j.jmarsys.2006.06.001.

Rouault, M., A. Mouche, F. Collard, J. Johannessen, and B. Chapron (2010), Mapping of the Agulhas current from space: An assessment of ASAR surface current velocities, J. Geophys. Res., 115, C10,026, doi:10.1029/2009JC006050.

Saji, N., B. Goswami, P. Vinayachandran, and T. Yamagata (1999), A dipole mode in the tropical Indian Ocean, Nature, 401, 360-363.

Schouten, M., W. de Ruijter, and P. van Leeuwen (2002), Upstream control of Agulhas ring shedding, J. Geophys. Res., 107, doi:10.1029/ 2001JC000804.

Siedler, G., M. Rouault, and J. Lutjeharms (2006), Structure and origin of the subtropical South Indian Ocean Countercurrent, Geophys. Res. Lett., 33, L24,609, doi:10.1029/2006GL027399.

Siedler, G., M. Rouault, A. Biastoch, B. Backeberg, C. Reason, and J. Lutjeharms (2009), Modes of the southern extension of the East Madagascar Current, J. Geophys. Res., 114, doi:10.1029/2008JC004921.

Stewart, R. (1989), The no-slip constraint and ocean models, Atmos. Ocean, $27,542-552$.

Sturges, W., and B. Hong (2001), Gulf stream transport variability at periods of decades, J. Phys. Oceanogr., 31, 1304-1312, doi:10.1175/ 1520-0485(2001)031<1304GSTVAP>2.0.CO;2.

Swallow, J., M. Fieux, and F. Schott (1988), The boundary currents east and north of Madagascar 1. Geostrophic currents and transports, J. Geophy. Res., 93(C5), 4951-4962, doi:10.1029/JC093iC05p04951.

Tourre, Y., and W. White (1997), Evolution of the ENSO signal over the Indo-Pacific domain, Journal of Physical Oceanography, 27, 683-696.

Tsugawa, M., and H. Hasumi (2010), Generation and growth mechanism of the natal pulse, J. Phys. Oceanogr., 40, 1597-1612, doi:10.1175/ 2010JPO4347.1.

van Leeuwen, P., and W. de Ruijter (2009), On the steadiness of separating meandering currents, J. Phys. Oceanogr., 39, 437-448, doi:10.1175/ 2008JPO3869.1. 